\title{
A Bird's-Eye View of Molecular Changes in Plant Gravitropism Using Omics Techniques
}

\author{
Oliver Schüler ${ }^{1,2}$, Ruth Hemmersbach ${ }^{1}$ and Maik Böhmer* \\ ${ }^{1}$ Institute of Aerospace Medicine, Gravitational Biology, German Aerospace Center, Cologne, Germany, ${ }^{2}$ Institute of Plant \\ Biology and Biotechnology, Westfälische Wilhelms Universität, Münster, Germany
}

During evolution, plants have developed mechanisms to adapt to a variety of environmental stresses, including drought, high salinity, changes in carbon dioxide levels and pathogens. Central signaling hubs and pathways that are regulated in response to these stimuli have been identified. In contrast to these well studied environmental stimuli, changes in transcript, protein and metabolite levels in response to a gravitational stimulus are less well understood. Amyloplasts, localized in statocytes of the root tip, in mesophyll cells of coleoptiles and in the elongation zone of the growing internodes comprise statoliths in higher plants. Deviations of the statocytes with respect to the earthly gravity vector lead to a displacement of statoliths relative to the cell due to their inertia and thus to gravity perception. Downstream signaling events, including

OPEN ACCESS

Edited by:

Rodrigo A. Gutierrez, Pontificia Universidad Catolica de Chile, Chile

Reviewed by: Ján A. Miernyk,

University of Missouri, USA Teva Vernoux,

Centre National de la Recherche

Scientifique, France

*Correspondence: Maik Böhmer

m.boehmer@uni-muenster.de

Specialty section:

This article was submitted to Plant Physiology,

a section of the journal

Frontiers in Plant Science

Received: 12 August 2015 Accepted: 08 December 2015 Published: 24 December 2015

Citation:

Schüler O, Hemmersbach $R$ and Böhmer M (2015) A Bird's-Eye View of Molecular Changes in Plant Gravitropism Using Omics Techniques. Front. Plant Sci. 6:1176. doi: 10.3389/fpls.2015.01176 the conversion from the biophysical signal of sedimentation of distinct heavy mass to a biochemical signal, however, remain elusive. More recently, technical advances, including clinostats, drop towers, parabolic flights, satellites, and the International Space Station, allowed researchers to study the effect of altered gravity conditions - real and simulated micro- as well as hypergravity on plants. This allows for a unique opportunity to study plant responses to a purely anthropogenic stress for which no evolutionary program exists. Furthermore, the requirement for plants as food and oxygen sources during prolonged manned space explorations led to an increased interest in the identification of genes involved in the adaptation of plants to microgravity. Transcriptomic, proteomic, phosphoproteomic, and metabolomic profiling strategies provide a sensitive high-throughput approach to identify biochemical alterations in response to changes with respect to the influence of the gravitational vector and thus the acting gravitational force on the transcript, protein and metabolite level. This review aims at summarizing recent experimental approaches and discusses major observations.

Keywords: gravity, plants, systems biology, proteomics, transcriptomics, metabolomics, spaceflight, microgravity

\section{PLANT RESPONSE TO DEVIATIONS FROM THE VERTICAL POSITION}

Gravitropism is defined as the bending of a plant/organ along the direction of the gravity vector. Positive gravitropism describes growth toward the gravity vector, e.g., growth of the root into the soil. Negative gravitropism defines growth opposed to the gravity vector, e.g., growth of the shoot into the air (Frank, 1868). Gravitropic signaling and the role of auxin in gravitropism has recently 
been reviewed (Lopez et al., 2014; Sato et al., 2015; Zadnikova et al., 2015). In this review we will only briefly discuss the current models of gravitropic responses and focus on the molecular changes measured by omics techniques.

In Arabidopsis roots, the root cap, which comprises of four tiers of columella cells and lateral root cap cells (Dolan et al., 1993), is known to be the site of gravity perception. Early decapping experiments showed a loss of the plant's gravitropic response. The ability to sense alterations of the gravity vector was recovered by regeneration of the root cap (Barlow, 1974). Particularly the inner cells of the second tier of columella cells contribute to root gravitropism as shown by laser ablation experiments (Blancaflor et al., 1998). The gravitropic response, on the other hand, takes place in the elongation zone of the root, physically separated from the site of perception.

In the shoot, mostly coleoptiles and pulvini of monocotyledons and hypocotyledons of dicotyledons were studied in respect to their gravitropic response (Sack, 1991). Genetic studies identified the endodermal cell layer in shoots as statocytes (Fukaki et al., 1998; MacCleery and Kiss, 1999).

Plant gravitropism can be divided into distinct phases: susception, perception, transduction, and response (curvature) (Perbal and Driss-Ecole, 2003; Limbach et al., 2005). Any alteration of the influence of the gravity vector is perceived with the help of specialized, starch-containing organelles, so called statoliths, in gravisensing cells (statocytes), which are sedimenting to the cell's new physiological bottom (Haberlandt, 1900; Caspar and Pickard, 1989; Kiss and Sack, 1989; Kuznetsov and Hasenstein, 1996; Kiss et al., 1997; Sack, 1997; Kiss, 2000; Morita, 2010). According to the starch-statolith hypothesis, sedimentation of the starch-filled amyloplasts triggers a signal transduction cascade leading to an asymmetric auxin transport and a curvature opposite of the gravitational vector. Additional models have been proposed, including the gravitational pressure hypothesis that is based on density differences and consequently the pressure exerted by the cytoplasm on the plasma membrane (Wayne et al., 1990; Wayne and Staves, 1996) or the tensegrity model, in which the membrane is outstretched on the cytoskeleton backbone of the cell and is in equilibrium between tensile and compressive forces (Ingber, 1997). The latter two models are in accordance with experimental data that still show a gravitropic response in starchless mutants (Caspar and Pickard, 1989). Statolith-dependent and -independent systems might also act in parallel (Perbal, 1999). In a refined model of the statolith hypothesis, it was suggested that not the pressure exerted by statolith sedimentation, but their interaction with membrane-bound receptors activates gravity perception (Braun and Limbach, 2006). In characean rhizoids, graviperception requires the contact of statoliths with membrane-bound receptor molecules rather than tension or pressure exerted by the weight of the statoliths (Limbach et al., 2005). Protein interactions between amyloplasts and membrane receptors might involve components of the TOC (TRANSLOCON OF OUTER MEMBRANE OF CHLOROPLASTS) complex (Stanga et al., 2009; Strohm et al., 2014). Experimental data so far, however, are controversial (Staves, 1997; Staves et al., 1997; Braun et al., 2002; Hou et al., 2003, 2004; Limbach et al., 2005; Valster and Blancaflor, 2008).
A common view is, that the biophysical signal of statolith sedimentation or of changes in cytoplasmic pressure is converted into a biochemical signal (Fasano et al., 2001; Plieth and Trewavas, 2002). Models have been put forward in which the sedimentation of statoliths leads to the activation of mechanosensitive ion channels at the plasmamembrane, endoplasmic reticulum, or at the tonoplast (Sievers et al., 1991; Yoder et al., 2001; Allen et al., 2003; Perbal and Driss-Ecole, 2003). In columella cells, the nucleus and the endoplasmic reticulum (ER) are localized at the proximal side of the root meristem and in the periphery of the cell. This ER, called nodal ER (Zheng and Staehelin, 2001), is thought to be a major reservoir for the second messenger $\mathrm{Ca}^{2+}$. Statoliths may induce opening of mechanosensitive ion channels under contribution of the nodal ER and second messenger release (Leitz et al., 2009). Alternatively, statoliths may facilitate the opening of mechanosensitive ion channels under contribution of the cytoskeleton (Sievers et al., 1991; Volkmann and Baluska, 1999; Perbal and Driss-Ecole, 2003). The role of the cytoskeleton is still controversially discussed, but recently the general view is, that the actin cytoskeleton is a negative regulator of root gravitropism (Blancaflor, 2013) and might play a role in fine-tuning the gravitropic response.

Calcium elevations are considered a second messenger of early gravitropic signaling events (Sinclair and Trewavas, 1997; Chen et al., 1999; Chatterjee et al., 2000). The contribution of $\mathrm{Ca}^{2+}$ to gravitropism was mainly concluded from inhibitor studies (Belyavskaya, 1996), calcium binding proteins (Stinemetz et al., 1987; Heilmann et al., 2001) or cellular messengers known to be related to $\mathrm{Ca}^{2+}$ signaling (Perera et al., 1999). Recent studies on Arabidopsis seedlings expressing the luminescent $\mathrm{Ca}^{2+}$ reporter Aequorin demonstrated transient increases in $\left[\mathrm{Ca}^{2+}\right]_{c y t}$ during the gravitropic response (Plieth and Trewavas, 2002; Toyota et al., 2008). Two waves of $\mathrm{Ca}^{2+}$ oscillations were observed, an initial transient $\mathrm{Ca}^{2+}$ increase after $3 \mathrm{~s}$ and a more sustained flux after 60 s (Toyota et al., 2008). Further second messengers, including Inositol 1,4,5- triphosphate $\left(\mathrm{IP}_{3}\right)$ (Perera et al., 1999, 2001a; Fasano et al., 2002), protons (Fasano et al., 2001), and reactive oxygen species (ROS; Joo et al., 2001) may also play a role in the gravitropic response. How these secondary messengers interact, their kinetics, and how they establish a response, remains unclear.

Signal transduction eventually leads to the relocalization of auxin carriers (Friml, 2003). Auxin is transported by influx carriers of the AUXIN RESISTANT 1/LIKE-AUX1 (AUX1/LAX) family and the efflux carriers of the PIN-FORMED (PIN) family (Friml, 2003). This transport is known as the "Chemiosmotic Hypothesis" (Kleine-Vehn and Friml, 2008) or Soda fountain model (Hasenstein and Evans, 1988). AUX1 and PIN1 contribute to auxin transport from vasculature into root tip through protophloem cells. In Arabidopsis, mutation in AUX1 results in severely agravitropic roots due to defects in auxin movements from the root apex to the distal elongation zone (Swarup et al., 2001). In the tip, PIN4 targets auxin to the center of the auxin maximum, which is located in the columella cells within the root cap. PIN3, PIN4, and PIN7 are localized in the columella cells. In this area, AUX1 ensures the uptake of auxin by columella cells, while the PIN proteins mediate efflux. PIN3 and PIN7 protein 
distribution is dependent on the orientation of the root in the gravitational field. When the root is growing vertically, PIN3 and PIN7 are distributed symmetrically in the cell. If there is any deviation from the vertical into the horizontal position, PIN3 and PIN7 relocalize within a few minutes. The efflux carriers are then accumulating in the plasma membrane of the cell's new physiological bottom (Friml et al., 2002a,b; Friml, 2003; Kleine-Vehn et al., 2010). The relocalization of PIN3 and PIN7 are the first steps toward the establishments of a lateral auxin gradient upon gravistimulation (Blancaflor and Masson, 2003). While the total auxin flux in the root stays constant, auxin is redistributed from cells on the upper to the lower side of the root tip within 5 min after a gravitropic stimulus (Band et al., 2012), a timescale that is in accordance with statolith sedimentation and asymmetric changes in root $\mathrm{pH}$ and intracellular $\mathrm{Ca}^{2+}$ concentration. pin 3 pin 7 mutants are more agravitropic than pin3 and pin 7 single mutants, suggesting their functional redundancy. The corresponding auxin gradient is transported basipetally through epidermal and cortical cells of the root cap that express PIN2. This efflux carrier transports auxin to the elongation zones of the root, which leads to root curvature (Chen et al., 1999; Ottenschlager et al., 2003).

PIN-FORMED protein abundance and localization at the plasma membrane affects gravitropic response. PIN proteins undergo constitutive endocytotic recycling to different domains at the plasma membrane or via the prevacuolar compartment to the lytic vacuole for degradation (Abas et al., 2006; KleineVehn and Friml, 2008). Modulation of vesicular trafficking affects PIN recycling and gravitropic response (Geldner et al., 2004; Paudyal et al., 2014). Recent results indicate that the polar auxin transport (PAT) mediated by PIN proteins can also be modulated by small secretory peptides called GOLVEN. A reduced concentration of those peptides impairs the formation of auxin gradients during tropic responses (Whitford et al., 2012). The GOLVEN signal specifically modulates PIN2 trafficking. Auxin as well as GOLVEN treatment increase PIN2 levels at the plasma membrane (Paciorek et al., 2005; Whitford et al., 2012). Furthermore, Gibberellic acid (GA) increases the level of PIN auxin transporters at the plasma membrane and promotes asymmetric auxin distribution during gravitropic curvature. A dilution and subsequent reduction in GA leads to an increased concentration of growth repressors of the DELLA protein family, which may reduce cell elongation rate (Band et al., 2012; Löfke et al., 2013).

Posttranslational modifications of PIN proteins additionally affect their role in gravitropism. The Ser/Thr kinase PINOID regulates PIN2-mediated basipetal auxin transport by regulating plasma membrane localization of PIN2 (Sukumar et al., 2009; Huang et al., 2010). PIN3 phosphorylation status can also affect root gravitropism (Ganguly et al., 2012). The D6 PROTEIN KINASE (D6PK) may regulate gravitropism via the phosphorylation status of PINs (Barbosa et al., 2014).

Despite the extensive regulation of PIN2, pin2 mutants are actually not very agravitropic (Chen et al., 1998; Luschnig et al., 1998; Blakeslee et al., 2007). A triple mutant together with members of the p-glycoprotein (PGP) family of auxin efflux transporters, PGP1 and PGP19, however, is severely agravitropic (Blakeslee et al., 2007), indicating functional redundancy in basipetal auxin transport.

The auxin gradient promotes differential cell elongation on opposing sides of the stimulated organ. Auxin is known to promote or to inhibit plant growth in a dose-dependent manner. Growth mediated by auxin is based on the acid-growth theory (Grebe, 2005). Auxin is able to activate proton pumps which lead to the excretion of protons into the cell wall. This acidification may lead to a loosening of the cell wall, allowing the cell to grow and expand. After the growth phase, the cell wall regains stability (Grebe, 2005). The result of an auxin-induced differential cell elongation is a gravitropic curvature.

Auxin can rapidly mediate tropic response on a minute to hour timescale while maintaining stable developmental zonation in the root and then slowly influences size and location of these differentiation zones via the regulation of PLETHORA (PLT) transcription factors (Mahonen et al., 2014). GOLVEN peptides act via positive regulation of PLETHORA transcription factors (Whitford et al., 2012).

Finally, statoliths reposition in the columella cells when the root tip reaches $40^{\circ}$, which leads to the restoration of PIN3/PIN7 localization and symmetric auxin flow, about $100 \mathrm{~min}$ after a $90^{\circ}$ gravitropic stimulus (Band et al., 2012; Sato et al., 2015). The latter phase of the root gravitropic bending response that can last up to $600 \mathrm{~min}$, is likely orchestrated by newly synthesized target genes of auxin signaling (Band et al., 2012).

\section{PLANTS' RESPONSE TO A MICROGRAVITY ENVIRONMENT}

Gravity is a constant factor of life on earth. With the aim to achieve functional weightlessness, a status which is often described as simulated microgravity, different approaches are in use, such as clinostats, random positioning machines as well as magnets for magnetic levitation (Herranz et al., 2013a). The rotation devices are based on the assumption that biological systems need to be exposed to the influence of the gravity vector for a minimal period of time to allow them to adjust to it. If the influence of the gravity vector constantly changes its orientation, the object loses under appropriate simulation conditions its sense of direction and thus shows a behavior similar to the one seen under real microgravity conditions. Real microgravity can be achieved by drop towers, parabolic flights, sounding rockets, satellites, or space stations, like the ISS. Experiment time is limited. Therefore, very little is known of how altered gravity is perceived by the plant and how the system adapts to this new environmental situation. A role for calcium elevations in response to microgravity, as in the response to reorientation of the plant, is still controversial (Häder et al., 2006; Salmi et al., 2011; Hausmann et al., 2014). A transcellular calcium gradient in spores of Ceratopteris richardii is reduced within seconds in microgravity, indicating a fast regulation of calcium channels similar to the auxin transport in the root tip during gravity perception (Salmi et al., 2011). In Arabidopsis callus cultures, instead, an increase in calcium and 
ROS was detected in response to microgravity (Hausmann et al., 2014).

Cellular responses that are affected by microgravity include the cell cycle, leading to decreased mitotic index and enhanced proliferation rate in meristematic root cells (Medina and Herranz, 2010). A second major target is the plant cell wall. In rice, a reduced thickness of the cell wall with increased extensibility and elongation in shoots and decreased elasticity in roots was observed (Hoson et al., 2002, 2003; Soga et al., 2003). Also changes in lignin levels in response to altered gravity forces have been observed in some plant species, e.g., mung beans, but not in others, e.g., pine and oat (Cowles et al., 1984). Changes in photosynthesis in response to microgravity, however, are controversial. While a reduction of the light harvesting apparatus and a higher chlorophyll a/chlorophyll b ratio was observed, direct measurements of photosynthetic activity revealed no changes in net photosynthesis, photosynthetic proton flux, and overall quantum yield (Stutte et al., 2006). The dependency of photosynthesis on gas exchange may be one reason for inconclusive results. The lack of convection in microgravity leads to reduced air flow resulting in altered gas exchange and accumulation of volatiles, e.g., ethylene (Porterfield, 2002), and is possibly leading to alterations in photosynthetic activity.

\section{EXPRESSION CHANGES IN RESPONSE TO A DEVIATION FROM THE VERTICAL ORIENTATION}

Complete sedimentation of the statoliths in the columella cells requires at least $5 \mathrm{~min}$ (Blancaflor et al., 1998; MacCleery and Kiss, 1999). The minimal gravitational stimulus that elicits a response, however, is estimated around $1 \mathrm{~min}$ (Blancaflor et al., 1998). Changes in secondary messenger concentration, e.g., IP3, $\mathrm{pH}$, and $\mathrm{Ca}^{2+}$, have been observed within this time frame. IP3 for example, is stimulated in gravitropic maize pulvini already after $10 \mathrm{~s}$ (Perera et al., 1999, 2001b). Observations of the early changes in gene expression may therefore help to identify missing components that translate the biophysical signal of statolith sedimentation into a biochemical signal (Table 1). Gravitational stimulation is generally achieved by one-time reorientation of plants in the gravity vector plane. In one of the earliest studies of Arabidopsis thaliana seedlings 39 genes showed an altered abundance after $15 \mathrm{~min}$ of gravitational stimulation, increasing to 132 genes after $30 \mathrm{~min}$ compared to constant $1 \mathrm{~g}$ conditions (Moseyko et al., 2002). Functional gene categories included response to oxidative stress, plant defense, heat shock, ethylene response, and calcium binding. Another study on gene expression changes, this time in root apices, identified gravity-specific gene regulations within 5$15 \mathrm{~min}$ of reorientation. A cluster of five genes was induced at least three fold by gravitropic stimulation even within $2 \mathrm{~min}$ of treatment (Kimbrough et al., 2004). The identified genes contained members of the auxin responsive family, genes that are induced very rapidly by the application of exogenous auxin (McClure and Guilfoyle, 1989). Taken together, these studies indicate that alterations of the influence of the gravitational vector is perceived as an abiotic stress signal when observed on the whole plant level, while in individual cells of plant organs involved in the gravitropic response, auxin signaling plays a major role in signal transmission.

The importance of auxin, also with respect to higher plants' shoot gravitropism, was underlined in at least three transcriptomic approaches. According to the Cholodny/Went hypothesis, an asymmetric auxin transport leads to a curvature in the direction of the gravitational vector (Went and Thimann, 1937). Auxin biosynthesis and signaling transcript levels changed after a deviation from the vertical position or in an already known agravitropic mutant (Esmon et al., 2006; Dong et al., 2013; Taniguchi et al., 2014). While no expression changes were observed after $10 \mathrm{~min}$, at $30 \mathrm{~min} 30$ genes changed in abundance, of which 19 transcripts were auxin responsive genes of the AUX/INDOLE-3-ACETIC ACID INDUCIBLE (IAA) and SMALL AUXIN UPREGULATED (SAUR) families (Taniguchi et al., 2014). Transcript analysis of plants of Zea mays wildtype and zmla1 mutant, a homolog of the Arabidopsis LAZY1 gene and an agravitropic mutant regulating PAT, identified 931 alterations in transcript expression. GO annotation of the altered genes and localization studies suggested a function for LAZY1 in auxin signaling and translocation of auxin exporters (PIN proteins) (Dong et al., 2013). When the focus was set on changes in gene expression in opposing flanks of graviresponsive tissue, e.g., hypocotyl, shoot base or inflorescence stems, a role for auxin in these responses became particularly clear (Esmon et al., 2006; Hu et al., 2013; Taniguchi et al., 2014). Two hours of gravitropic and phototropic stimulation of Brassica oleracea identified eight genes with increased expression in elongating versus non-elongating hypocotyl flanks under both stimuli. All are members of auxin biosynthesis [GLYCOSIDE HYDROLASE 3.5 (GH3.5)], signaling (SAUR50), and response (EXPANSIN A1) (Esmon et al., 2006). In addition, all eight genes contain at least one consensus AUXIN RESPONSE FACTOR (ARF)-binding auxin response element and no auxin-induced expression was observed in an ARF7 mutant background.

Studies also show that gene regulations in response to gravitational or mechanical stimulations showed a great overlap. In whole Arabidopsis seedlings, 55 of the 141 identified genes, changed in abundance by gravitational stimulation, increased or decreased in transcript levels by mechanical stimulation (Moseyko et al., 2002). An even greater overlap between mechanical and gravitational stimulation was found in root apices, where 1730 genes were differentially regulated within 60 min of gravitropic or mechanical stimulation (Kimbrough et al., 2004). The alterations on the transcript level induced by both stimuli overlap by $96 \%$. Many of the altered transcripts show increased or decreased levels in other abiotic and biotic stresses, too. They have functions as transcriptional regulators, in cell wall modification, as transporters, kinases, phosphatases, in hormone metabolism and in the cell cycle.

The first proteomic experiment to map changes in protein expression used 2D-GE and identified 16 alterations on the protein level in A. thaliana roots within $2 \mathrm{~h}$ of gravitational stimulation, some of them showing an altered abundance after 30 min (Kamada et al., 2005). Functional categories included 
TABLE 1 | Studies that quantified differential expression of genes, proteins, and metabolites in response to a deviation from the vertical orientation.

\begin{tabular}{|c|c|c|c|c|c|c|c|c|}
\hline Plant age $^{1}$ & Tissue & Replicates & Method & Duration & DEG/DEP/DEM & Growth hardware & Treatment & Reference \\
\hline \multicolumn{9}{|c|}{ Transcriptomics } \\
\hline 3 weeks & $\begin{array}{l}\text { A. thaliana } \\
\text { seedlings }\end{array}$ & 3 & 8 k array & $15,30 \mathrm{~min}$ & $\begin{array}{l}15 \text { min: } 39 \\
30 \text { min: } 132\end{array}$ & $\begin{array}{l}\text { Petri dish, white } \\
\text { light, transfer to } \\
\text { dark } 16 \text { h prior to } \\
\text { treatment }\end{array}$ & $90^{\circ}$ (dark) & $\begin{array}{l}\text { Moseyko et al., } \\
2002\end{array}$ \\
\hline 1 week & $\begin{array}{l}\text { A. thaliana root } \\
\text { apices }\end{array}$ & 2 & ATH1 & $\begin{array}{l}2,5,15,30 \\
60 \min \end{array}$ & 1730 & Petri dish, dark & $135^{\circ}$ (dark) & $\begin{array}{l}\text { Kimbrough } \\
\text { et al., } 2004\end{array}$ \\
\hline 3 days & $\begin{array}{l}\text { B. oleracea } \\
\text { etiolated seed- } \\
\text { lings, upper } \\
\text { and lower } \\
\text { flanks of } \\
\text { hypocotyl } \\
(1 \mathrm{~cm})\end{array}$ & 3 & ATH1 & $2 \mathrm{~h}$ & 8 & Pipette tips, dark & $90^{\circ}$ (dark) & $\begin{array}{l}\text { Esmon et al., } \\
2006\end{array}$ \\
\hline 3 weeks & $\begin{array}{l}\text { O. sativa, upper } \\
\text { and lower } \\
\text { flanks of shoot } \\
\text { base }\end{array}$ & 3 & $\begin{array}{l}\text { Rice Genome } \\
\text { GeneChip }\end{array}$ & $30 \mathrm{~min}, 6 \mathrm{~h}$ & $\begin{array}{l}30 \text { min: } 167 \\
6 \text { h: } 1202\end{array}$ & $\begin{array}{l}\text { Soil, white light, } \\
\text { transfer to dark } \\
16 \text { h prior to } \\
\text { treatment }\end{array}$ & $90^{\circ}$ (dark) & Hu et al., 2013 \\
\hline 4-8 cm stem & $\begin{array}{l}\text { A. thaliana, } \\
\text { upper and } \\
\text { lower flanks of } \\
\text { inflorescence } \\
\text { stems }\end{array}$ & 1 & Arabidopsis 2 & $10,30 \mathrm{~min}$ & $\begin{array}{l}10 \text { min: } 0 \\
30 \text { min: } 30\end{array}$ & Soil, white light & $90^{\circ}$ (light) & $\begin{array}{l}\text { Taniguchi et al., } \\
2014\end{array}$ \\
\hline 4 weeks & $\begin{array}{l}\text { Z. mays, third } \\
\text { aboveground } \\
\text { node of shoot }\end{array}$ & 2 & RNAseq & - & 931 & Soil, white light & - & $\begin{array}{l}\text { Dong et al., } \\
2013\end{array}$ \\
\hline \multicolumn{9}{|l|}{ Proteomics } \\
\hline 1 week & $\begin{array}{l}\text { A. thaliana, root } \\
\text { apices }\end{array}$ & 3 & 2D-GE & $30 \mathrm{~min}, 3 \mathrm{~h}$ & 16 & $\begin{array}{l}\text { Petri dish, white } \\
\text { light }\end{array}$ & $90^{\circ}$ (light) & $\begin{array}{l}\text { Kamada et al., } \\
2005\end{array}$ \\
\hline 8-10 cm stem & $\begin{array}{l}\text { A. thaliana, top } \\
4 \mathrm{~cm} \text { of shoot }\end{array}$ & 3 & iTRAQ & $2,4 \mathrm{~min}$ & 82 & Soil, white light & $90^{\circ}$ (light; $\left.4^{\circ} \mathrm{C}\right)$ & $\begin{array}{l}\text { Schenck et al., } \\
2013\end{array}$ \\
\hline \multicolumn{9}{|c|}{ Transcriptomics and Metabolomics } \\
\hline 1 week & $\begin{array}{l}\text { A. thaliana, } \\
\text { whole seedlings }\end{array}$ & 1 n.a. & ATH1 GC-MS & $24 \mathrm{~h}$ & $\begin{array}{l}\text { Genes: } 339 \\
\text { Metabolites: } 15\end{array}$ & $\begin{array}{l}\text { Petri dish, white } \\
\text { light }\end{array}$ & $90^{\circ}$ (dark) & $\begin{array}{l}\text { Millar and Kiss, } \\
2013\end{array}$ \\
\hline
\end{tabular}

${ }^{1}$ At start of treatment; DEG/DEP/DEM: differentially expressed genes, proteins, metabolites; n.a.: information not available; Rep: number of biological replicates.

$\mathrm{Ca}^{2+}$ signaling, cytoskeleton stability, energy production, TCA cycle and chaperone function. Furthermore, a shift in the apparent molecular weight of proteins due to gravitropic responses was observed that may be caused by an altered glycosylation pattern. One of those proteins with a change in molecular weight is the 20S PROTEASOME $\beta$-SUBUNIT E1. According to the authors, the chaperone HEAT SHOCK COGNATE 70-2 and the proteasomal subunit may regulate dynamic processes involved in the response to changes of the gravitational vector.

In order to identify proteins involved in early signaling events, e.g., the conversion from the biophysical signal of sedimentation of amyloplasts to a biochemical stimulus, a study on Arabidopsis shoots focused on the early perception and signaling events of plants subjected to 2 and $4 \mathrm{~min}$ of a deviation from the vertical. To identify less-/agravitropic signaling mutants, the authors performed plant reorientations at $4^{\circ} \mathrm{C}$, an approach known as the gravity-persistent signal (GPS) approach (Wyatt et al., 2002). GPS blocks the asymmetric auxin transport resulting in a lack of gravitropic curvature. If transferred back to room temperature the plant regains a bending phenotype. Using GPS treatment, 82 alterations on the protein level after gravitational stimulation were identified (Schenck et al., 2013). Thirty-five percent of the differentially expressed proteins were predicted to localize to chloroplasts or plastids, consistent with the hypothesis that gravity-sensing is related to these organelles (Kiss et al., 1989).

Promising candidates that were identified as being an important part of the perception of the gravitational vector and subsequent signaling are HEAT SHOCK PROTEIN 81-1 and GLUTATHIONE S-TRANSFERASE PHI 9 (GSTF9) and GSTF20. HSP81-1 is involved in abiotic stress signaling, induced by $\mathrm{Ca}^{2+}$ signaling and may interact with J-domain containing proteins like ALTERED RESPONSE TO GRAVITY 1 and ARG1LIKE 2 that are already known to show reduced gravitropism (Sedbrook et al., 1999; Guan et al., 2003). GSTF9 and GSTF20 may regulate the synthesis of plant hormones or subsequent signaling (Chen et al., 2007; Schenck et al., 2013).

The first transcriptomic and metabolomic approach was a combined treatment of gravi- and photostimulation (blue or red light) of Arabidopsis seedlings (Millar and Kiss, 2013). Despite the current methodical limitations in quantification of 
primary metabolites, the incorporation of metabolomic profiling into gravitational research was overdue, because this level is the last step prior to the physiological response. Gravity and light treatments led to shifts in amino acid pools (e.g., alanine, asparagine, glutamine, glycine, and isoleucine), decrease of sucrose and increase of hexoses, as well as decreased levels of secondary metabolites. Many of these altered primary metabolites are responsive to abiotic and biotic stresses, underlining the hypothesis of gravitropism and phototropism as exogenous stress stimuli of plants. As an example, changes in the pool of phenylalanine may lead to alterations in flavonoid biosynthesis. Those secondary metabolites are known to have an important function in the crosstalk between ethylene and auxin (Muday et al., 2012). On the transcript level, a $90^{\circ}$ treatment for $24 \mathrm{~h}$ resulted in 339 alterations in gene abundance. Regulations on the transcript level could be correlated to changes on the metabolite level (Millar and Kiss, 2013). Increased levels of key enzymes of amino acid biosynthesis, THREONINE ALDOLASE 1 and GLUTAMINE-DEPENDENT ASPARAGINE SYNTHASE 1, explain the increase of corresponding metabolites. The altered abundance of carbohydrate metabolism enzymes explains a decrease in sucrose and increase in hexose sugars. Key enzymes of phenylpropanoid biosynthesis, e.g., CHALCONE SYNTHASE, are decreased in abundance.

Results of all studies indicate that changes of the influence of the gravitational vector lead to a general stress response in plants. Analyses on the proteomic and metabolomic level (Kamada et al., 2005; Millar and Kiss, 2013; Schenck et al., 2013) further support the hypothesis that an altered influence of the gravity vector is perceived as environmental stress (Millar and Kiss, 2013; Schenck et al., 2013), emphasizing the contribution of cytoskeleton, calcium signaling and chaperone function to plant's gravitational response. In tissue specific transcriptomic studies, roots or opposing tissue flanks of the shoot, the importance of the phytohormone auxin is underlined. Already after $2 \mathrm{~min}$ alterations in auxin responsive genes were observed (Kimbrough et al., 2004). Furthermore, genes of auxin biosynthesis, signaling and response are differentially regulated (Esmon et al., 2006; Dong et al., 2013; Taniguchi et al., 2014). These findings support the widely accepted Cholodny/Went theory, suggesting auxin as a driving factor of tropic responses. A lack of an auxin response in whole seedlings may be caused by a higher dilution of auxin biosynthesis, signaling and response genes in whole seedling RNA, because the action of the phytohormone is restricted to some cell layers in specialized tissues.

\section{SIMULATED MICROGRAVITY AND SPACEFLIGHT}

Plants are potential components of future life support systems for manned space travels. For this, plant responses to the space environment, and in particular to microgravity, have to be studied (Table 2). Transcriptomic and proteomic studies have been performed toward this goal. In contrast to reorientation experiments, spaceflight and real microgravity experiments pose additional challenges. A suitable hardware providing optimal culture and illumination conditions has to be developed and further spaceflight-related effects on plants have to be taken into account such as increased levels of radiation, poor exchange of gases due to the lack of convection, vibrations, and accelerations depending on the transport systems and operations onboard (Porterfield et al., 1997).

In order to avoid some of these additional environmental effects and allow a discrimination of pure microgravity-related effects, $1 \mathrm{~g}$ controls are essential. Under optimal conditions these are realized by the use of onboard $1 \mathrm{~g}$ reference centrifuges. It is, however, in most cases common to compare space flight samples to corresponding $1 \mathrm{~g}$ ground controls. Efforts have been made to replicate the growth conditions in space for the ground controls by using orbital environment simulators (OES) that replicate light, temperature and $\mathrm{CO}_{2}$ conditions as recorded in space. Studies utilizing both controls show that more alterations in gene expression are observed comparing plants from space flight (SF) to ground controls (GC) than to on board $1 \mathrm{~g}$ flight controls (FC) (Correll et al., 2013; Fengler et al., 2015), suggesting that factors independent of gravity and operational-induced side effects have a profound effect on plant growth and development.

Another consideration is the age of plants that are transported into orbit. Dried seeds do not correspond to environmental changes during the transport phase. Callus cultures and plants that are transported as seedlings or fully grown, however, experience transient changes in accelerations, $1 \mathrm{~g}$ on ground, hypergravity during flight phase and microgravity in orbit, and other changes in growth conditions that are not only a result of the space environment.

Different experimental conditions therefore have a great effect on the responses of plants to the space environment. In leaves of wheat, for example, no changes in gene expression were detectable between ground control and space-grown plants (Stutte et al., 2006). Growth of Arabidopsis seedlings during space flight though, led to the alteration of 480 genes compared to ground controls (Paul et al., 2013). The latter study was also the first one to study responses in different plant organs separately, indicating that different organs display unique patterns of gene expression in response to spaceflight. From a total of 480 genes that were differentially expressed in leaves, hypocotyls, or roots, only 26 genes were uniformly regulated in all three organs, many of those being involved in cell wall remodeling.

Arabidopsis plants grown in a spaceflight environment are usually smaller than ground controls, possess smaller roots and fewer lateral roots (Paul et al., 2012a). The cell wall of Arabidopsis and rice plants is reduced in response to the spaceflight environment (Hoson et al., 2002, 2003; Soga et al., 2002). Furthermore, cell wall extensibility of shoots is increased, while the cell wall flexibility of roots is decreased, as compared to ground controls (Hoson et al., 2003). Transcriptomic and proteomic approaches showed transcripts and proteins associated with cell wall remodeling, root hair generation and cell expansion to be highly altered during spaceflight (Paul et al., 2012b, 2013; Correll et al., 2013; Mazars et al., 2014b; Fengler et al., 2015; Ferl et al., 2015; Kwon et al., 2015; Zhang et al., 2015) or during clinorotation and random positioning (Wang et al., 2006; Barjaktarović et al., 2009). Alterations in 


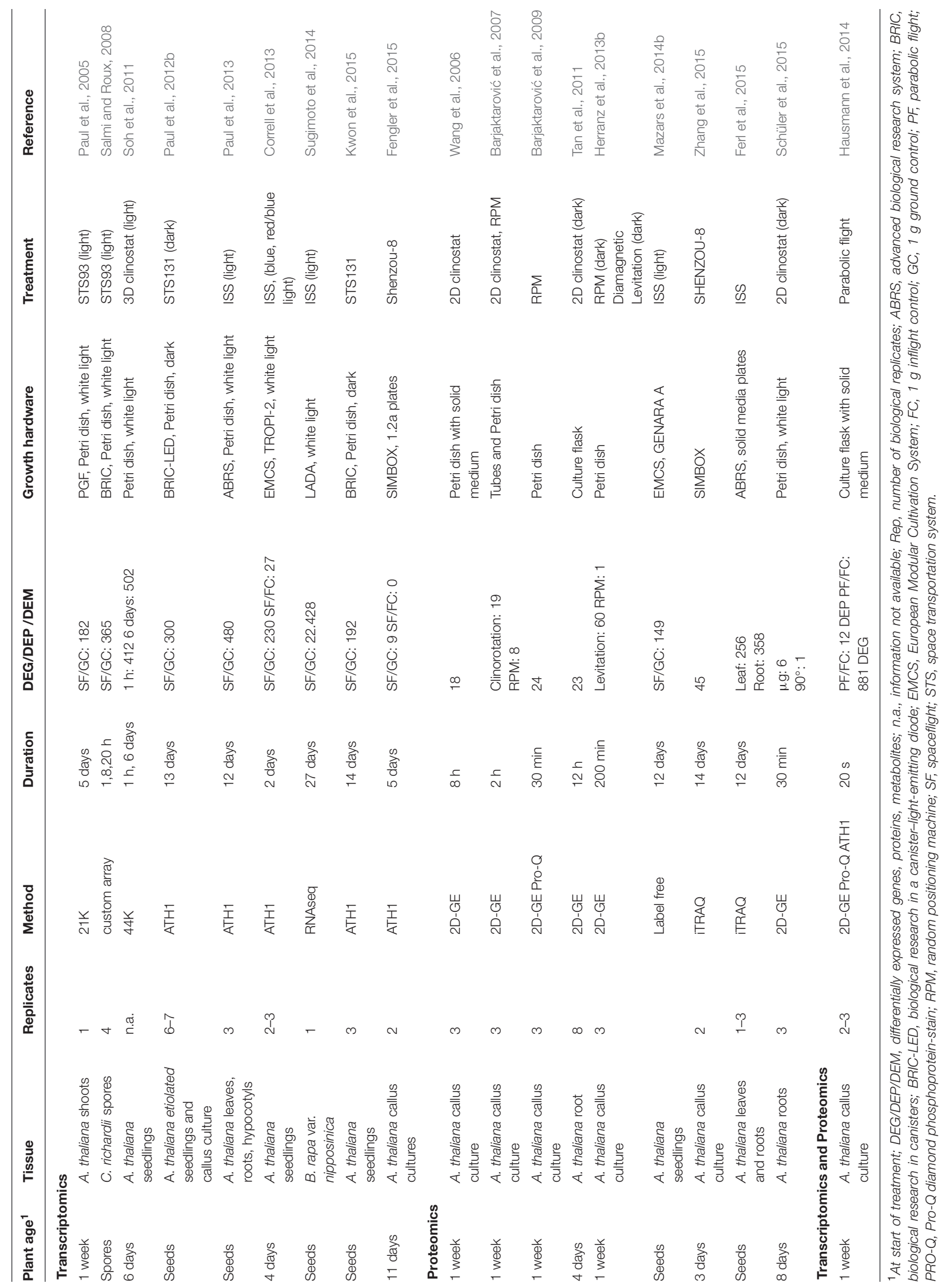


gene expression that have a function in cell wall modification could be caused by spaceflight-induced changes in several hormone signaling pathways that are mediating growth and cell expansion. By using spaceflight $1 \mathrm{~g}$ controls and $1 \mathrm{~g}$ ground controls to elucidate the response to microgravity and exclude indirect effects by the spaceflight, 27 strictly graviresponsive transcripts were identified that were altered at least twofold in abundance, including genes of cell wall metabolism and actin cytoskeleton organization (Correll et al., 2013). By regulating the transport of cell wall components, the actin cytoskeleton is essential for a proper biosynthesis of the cell wall (Baluska et al., 2002). Also proteomic studies of Arabidopsis microsomes and callus cultures supported the involvement of cell wall modifications (Mazars et al., 2014b). A subsequent comparison of $1 \mathrm{~g}$ space control and $1 \mathrm{~g}$ ground controls of the same flight could furthermore show that cell wall modifying proteins are largely not altered on the protein level, suggesting that cell wall modifying enzymes are necessary for a response specifically to microgravity (Mazars et al., 2014a; Zhang et al., 2015). A comparison of different studies furthermore showed that regulation of protein activity occurs on multiple levels. REVERSIBLY GLYCOSYLATED POLYPEPTIDEs, involved in cell wall metabolism, did not only show a decreased abundance on the protein level (Wang et al., 2006; Schüler et al., 2015), but were also phosphorylated in response to clinorotation (Barjaktarović et al., 2009). Phosphorylation was suggested to affect the activity of the proteins and thereby cell wall metabolism.

In addition to changes in primary and lateral roots, Arabidopsis seedlings grown in space experience reduced root hair development (Kwon et al., 2015). This decrease may be due to reduced levels of peroxidases and cell wall modifying genes (Kwon et al., 2015). Out of 174 transcripts showing an altered abundance, 56 are enriched in root hairs and eight were shown to function in root hair development. Mutations in those peroxidases with a decreased abundance by spaceflight, led to a disruption of root hair formation in Arabidopsis (Kwon et al., 2015).

In other comparable spaceflight experiments, genes involved in production and response to ROS were altered (Paul et al., 2012b; Correll et al., 2013). A change in ROS levels is a secondary messenger of many abiotic and biotic stresses in plants (Apel and Hirt, 2004). ROS concentrations in the cell are kept in balance by an interplay of ROS production and scavenging via different enzymes and metabolites (Pitzschke and Hirt, 2006). Spaceflight/microgravity affects genes involved in ROS production and homeostasis by up- or downregulation. Increase in hydrogen peroxide levels and increased expression and phosphorylation of ROS scavengers, e.g., SUPEROXIDE DISMUTASE, CATALASE, GLUTATHIONE PEROXIDASE, THIOREDOXIN, and GLUTAREDOXIN, and marker genes were measured in short-term and long-term experiments (Hausmann et al., 2014; Sugimoto et al., 2014). Also in microgravity simulated by clinorotation, genes with antioxidant activity showed increased expression levels in response to shortterm and long-term microgravity (Soh et al., 2011). In contrast, proteins of the response to oxidative stress were decreased in Arabidopsis calli and in C. richardii spores (Salmi and Roux, 2008;
Zhang et al., 2015). This may indicate that different isoform of gene families are differentially regulated, as was directly observed in some studies (Barjaktarović et al., 2007; Fengler et al., 2015). ROS changes in plants might be a direct result of auxin signaling. In response to microgravity treatment of roots from wildtype and pin 2 mutant plants, a peroxidase was identified that showed altered levels in the wildtype, but not in the mutant (Tan et al., 2011).

In order to maintain ROS homeostasis for cell function and for signaling, proteins involved in this process are likely to be also posttranslationally regulated. Phosphoproteomic studies show a differential phosphorylation in response to $30 \mathrm{~min}$ of microgravity of proteins which are responsive to ROS (Barjaktarović et al., 2009). Taken together, these observations indicate that a complex regulation of antioxidant enzymes is necessary to maintain ROS homeostasis under microgravity, and that different levels of regulation are involved in this process.

Besides ROS, also transcripts involved in calcium signaling are altered under space conditions (Salmi and Roux, 2008; Soh et al., 2011; Paul et al., 2012b; Correll et al., 2013; Mazars et al., 2014b). Plants respond to a spaceflight environment with disruptions of calcium localization and signaling (Klymchuk et al., 2001; Nedukha et al., 2001; Salmi and Roux, 2008). Increase in calcium concentrations have been measured using genetically encoded reporters within 20 s of microgravity during parabolic flights (Hausmann et al., 2014). In addition, up to 25 calcium dependent genes were upregulated at the end of the $20 \mathrm{~s}$ microgravity phase. A proteomic approach focusing on microsomal membranes found further evidence for a link between calcium and auxin signaling in response to microgravity. PHOTOTROPIN 2 (PHOT2) is decreased in abundance after 12 days of space flight (Mazars et al., 2014b). PHOT2 is a blue light receptor and can trigger intracellular calcium increases. It was suggest that the calcium increase activates calcium sensors, such as TOUCH3 and PINOID BINDING PROTEIN 1 (PBP1) that interact with the AGC kinase PINOID (PID), a regulator of PAT (Mazars et al., 2014a). In the same experiment, TOUCH3 protein abundance was increased fourfold at the plasma membrane, indicating a calcium dependent regulation of PAT in response to microgravity. This hypothesis was further supported by decreased levels of CATION EXCHANGER 1, a protein of the vacuolar membrane that drives calcium influx from the cytosol to the vacuole, which leads to an increased cytosolic calcium concentration.

Taken together, these data point toward a similar response mechanism in microgravity as described for the reorientation of plants in the gravitational field. In microgravity, calcium is increased, thereby activating calcium binding proteins, leading to the activation of kinases, including CPK11 and PINOID. Calcium influx may directly trigger production of ROS, e.g., via the activation of calcium dependent protein kinases, or indirectly via changes in auxin transport within the plant.

Tissues involved in the perception of the gravitational stimulus, e.g., the root cap, express all proteins necessary for this signaling model. However, other cell types, e.g., undifferentiated cell cultures, are also able to detect a loss of the influence of gravity (microgravity) without specialized 
gravisensing tissue (Martzivanou et al., 2006). In these cells, altered ROS production in response to changes in the influence of the gravitational field might be a result of general, but tissue-specific stress responses (Wang et al., 2006; Barjaktarović et al., 2007, 2009, Salmi and Roux, 2008; Herranz et al., 2013b; Fengler et al., 2015). Also in whole seedlings subjected to simulated microgravity or spaceflight, transcripts of stress related genes are oftentimes altered (Kwon et al., 2015). Short-term microgravity environments, e.g., parabolic flights, thereby induce similar transcript changes, i.e., cell wall, heat shock, response to hormones, which are also observed after long term spaceflight experiments. Transcripts of functionally related genes were regulated in different tissues. Expression of individual isoforms, however, was specific to different plant organs (Paul et al., 2013). A comparison of Arabidopsis callus cultures and seedlings grown in the same hardware showed two independent responses to spaceflight without similarities in transcript alterations (Paul et al., 2012b). In seedlings as well as callus cultures a response to abiotic and biotic stress was clearly detectable, but more pronounced in cell cultures (Paul et al., 2012b). The response to heat shock is the most prominent Gene Ontology (GO) in cell cultures followed by a general stress response (Paul et al., 2012b; Zupanska et al., 2013). Also in Arabidopsis shoots changes in HSP transcripts were observed (Paul et al., 2005). When plant responses to changes of the orientation with respect to the gravitational vector or to changes of intensity of the gravitational field were analyzed in the same study, HSP70-3 was the only protein with altered levels under both conditions (Schüler et al., 2015). Taking into account that the spaceflight environment includes several abiotic stresses, e.g., radiation, microgravity, or vibrations, over-expression of heat shock proteins may contribute to generalized tolerance for multiple alterations in environment conditions and may help to maintain cytoskeletal architecture, cell shaping, and protein remodeling (Swindell et al., 2007; Zupanska et al., 2013).

The notion that microgravity may constitute an abiotic stress, led some authors to screen for genes involved in Simulated Microgravity Stress (SMS; Soh et al., 2011). SMSgenes including WRKY transcription factors and phytohormone induced signaling transcripts were identified. On this gene list, some transcripts are known to be responsive to other biotic/abiotic stresses, too. This is supported by a proteomic approach that identified 18 altered proteins in Arabidopsis cell culture after $8 \mathrm{~h}$ of 3D clinorotation (Wang et al., 2006). Seven alterations are involved in stress responses (e.g., ALDEHYDE DEHYDROGENASE 2, GST, and CHITINASE). Also in seedlings, proteins, with an altered abundance, and being involved in general stress responses, were identified (Mazars et al., 2014b).

In summary, experimental approaches to impose changes of the gravitational field vary significantly in experimental setup and plant material. However, some common conclusions can be drawn from these studies. The plant cell wall and actin cytoskeleton are major targets for modifications. Earlier studies clearly show a spaceflight-induced cell wall thinning (Hoson et al., 2002, 2003). Root hair growth is also highly reduced in space (Kwon et al., 2015). The authors suggest a role of ROS in the alteration in growth. Results from further studies suggest that cell wall modifications of plants subjected to spaceflight may be directed by changes to the actin cytoskeleton (Correll et al., 2013; Mazars et al., 2014b).

Another response to simulated microgravity and spaceflight seems to be a general response to abiotic and biotic stresses. Especially cell cultures show a heat shock response. Those chaperones may help to maintain cytoskeletal architecture and cell shaping in a spaceflight environment (Zupanska et al., 2013). Furthermore, the biosynthesis and response to phytohormones and calcium signaling is altered under simulated microgravity and spaceflight conditions supporting the hypothesis that a highly reduced gravity environment resembles an abiotic and/or biotic stress in plant tissues (Salmi and Roux, 2008; Soh et al., 2011; Correll et al., 2013; Mazars et al., 2014b). Another stress marker is the change in cellular ROS levels. In some of the reviewed publications an increase of ROS scavengers (Sugimoto et al., 2014), an elevated level in hydrogen peroxide (Hausmann et al., 2014) and an alteration of genes with antioxidant activity (Soh et al., 2011) was shown if plants were subjected to spaceflight or simulated microgravity. In addition, dependency of some responses on the PIN2 auxin transporter and changes in calcium concentrations point towards a signaling mechanism in microgravity, involving calcium, ROS and auxin, that is comparable to the response to a reorientation in the gravitational field.

\section{CONCLUSION/FUTURE PERSPECTIVES}

The reviewed studies identified molecular components of plant responses to changes in the gravitational field or vector. It was previously known that calcium and auxin play a role in these processes. Omics profiling strategies allowed the identification of underlying genes and proteins with altered abundance by these messengers or that affect the function of these messengers. Especially alterations in the concentration of auxin biosynthesis (GH3.5) and auxin responsive (AUX/IAA, SAUR) genes have been observed. A comparison of these studies furthermore indicates that different plant organs and callus cultures respond differently to changes in the influence of gravity. More cell type specific studies are necessary to identify how different cell types respond and how these cell types interact to form plant responses. Since experimental time in space is limited, experiments in ground-based facilities (GBFs) will be extensively needed to compensate for space experiments and to provide the necessary number of replicates for robust results.

Hardware-specific differences between individual studies as well as differential operations of GBFs contribute to difficulties in understanding plant responses to changes in the influence of the gravitational field. Standardization of growth and experimental hardware has to be pursued for ground-based and flight facilities (Schüler et al., 2015). Validated operational parameters of simulation approaches and $1 \mathrm{~g}$ flight control will have to be an essential component in all space flight experiments. The 
generation of more robust data would also benefit from scientific collaborations that perform the same experiments over multiple missions using standardized hardware. Sequential extraction protocols for RNA, proteins and metabolites would also reduce biological material and facilitate analyses across different levels of responses.

One of the main tasks for the future will be the integration of different datasets, covering various levels of cellular responses, ions, transcript changes, proteins, and hormones, into a common database to allow researchers to cross-analyse all results between different experimental conditions, tissues, and organisms. This will increase statistical power as compared to individual analyses with limited biological replicates. Larger datasets also allow for the development of mathematical models that are both descriptive and predictive and enable the generation of testable hypotheses. Complementary to broad omics techniques, reporter techniques with single cell resolution, e.g., genetically encoded hormone-, $\mathrm{pH}$ - and $\mathrm{Ca}^{2+}$-reporters, should be used to study signaling events and signal transmission, e.g., from the columella cells to the elongation zone. Suitable hardware to study single cell response to changes in the influence of the gravitational vector is available in the form of microscopes

\section{REFERENCES}

Abas, L., Benjamins, R., Malenica, N., Paciorek, T., Wisniewska, J., MoulinierAnzola, J. C., et al. (2006). Intracellular trafficking and proteolysis of the Arabidopsis auxin-efflux facilitator PIN2 are involved in root gravitropism. Nat. Cell Biol. 8, 249-256. doi: 10.1038/ncb1369

Allen, N. S., Chattaraj, P., Collings, D., and Johannes, E. (2003). Gravisensing: ionic responses, cytoskeleton and amyloplast behavior. Adv. Space Res. 32, 1631-1637. doi: 10.1016/s0273-1177(03)90404-90402

Apel, K., and Hirt, H. (2004). Reactive oxygen species: metabolism, oxidative stress, and signal transduction. Annu. Rev. Plant Biol. 55, 373-399. doi: 10.1146/annurev.arplant.55.031903.141701

Baluska, F., Hlavacka, A., Samaj, J., Palme, K., Robinson, D. G., Matoh, T., et al. (2002). F-actin-dependent endocytosis of cell wall pectins in meristematic root cells. Insights from brefeldin A-induced compartments. Plant Physiol. 130, 422-431. doi: 10.1104/pp.007526

Band, L. R., Wells, D. M., Larrieu, A., Sun, J., Middleton, A. M., French, A. P., et al. (2012). Root gravitropism is regulated by a transient lateral auxin gradient controlled by a tipping-point mechanism. Proc. Natl. Acad. Sci. U.S.A. 109, 4668-4673. doi: 10.1073/pnas.1201498109

Barbosa, I. C., Zourelidou, M., Willige, B. C., Weller, B., and Schwechheimer, C. (2014). D6 PROTEIN KINASE activates auxin transport-dependent growth and PIN-FORMED phosphorylation at the plasma membrane. Dev. Cell 29, 674-685. doi: 10.1016/j.devcel.2014.05.006

Barjaktarović, Z., Nordheim, A., Lamkemeyer, T., Fladerer, C., Madlung, J., and Hampp, R. (2007). Time-course of changes in amounts of specific proteins upon exposure to hyper-g, 2-D clinorotation, and 3-D random positioning of Arabidopsis cell cultures. J. Exp. Bot. 58, 4357-4363. doi: 10.1093/jxb/erm302

Barjaktarović, Ž., Schütz, W., Madlung, J., Fladerer, C., Nordheim, A., and Hampp, R. (2009). Changes in the effective gravitational field strength affect the state of phosphorylation of stress-related proteins in callus cultures of Arabidopsis thaliana. J. Exp. Bot. 60, 779-789. doi: 10.1093/jxb/ern324

Barlow, P. (1974). Regeneration of the cap of primary roots of Zea mays. New Phytol. 73, 937-954. doi: 10.1111/j.1469-8137.1974.tb01323.x.

Belyavskaya, N. A. (1996). "Calcium and graviperception in plants: inhibitor analysis," in International Review of Cytology, ed. W. J. Kwang (Waltham, MA: Academic Press), 123-185.

Blakeslee, J. J., Bandyopadhyay, A., Lee, O. R., Mravec, J., Titapiwatanakun, B., Sauer, M., et al. (2007). Interactions among PIN-FORMED and with a vertical sample stage. Microscopes for cell specific studies under microgravity conditions have also been made available.

Next logical steps after the development of testable mathematical models are physiological tests of the coding genes by experiments with mutant lines and overexpression lines. These are necessary to further corroborate their function in gravitational responses. Limitation in experiments with transgenic plants in space and ground-based facilities can be overcome with the application of chemically mutagenized lines or newer techniques, e.g., CRISPR/Cas.

\section{ACKNOWLEDGMENTS}

Research activities in the authors' laboratories are supported by research grants from the European Space Agency (4000109583ESA-CORA-GBF-2013-005-BÖHMER) to MB, the Bundesministerium für Wirtschaft und Energie/Deutsches Zentrum für Luft- und Raumfahrt (FLORENCE) to $\mathrm{MB}$ and a Helmholtz Space Life Sciences Research School (SpaceLife) scholarship to OS.

P-glycoprotein auxin transporters in Arabidopsis. Plant Cell 19, 131-147. doi: $10.1105 /$ tpc. 106.040782

Blancaflor, E. B. (2013). Regulation of plant gravity sensing and signaling by the actin cytoskeleton. Am. J. Bot. 100, 143-152. doi: 10.3732/ajb. 1200283

Blancaflor, E. B., Fasano, J. M., and Gilroy, S. (1998). Mapping the functional roles of cap cells in the response of arabidopsis primary roots to gravity. Plant Physiol. 116, 213-222. doi: 10.1104/pp.116.1.213

Blancaflor, E. B., and Masson, P. H. (2003). Plant gravitropism. Unraveling the ups and downs of a complex process. Plant Physiol. 133, 1677-1690. doi: 10.1104/pp.103.032169

Braun, M., Buchen, B., and Sievers, A. (2002). Actomyosin-mediated statolith positioning in gravisensing plant cells studied in microgravity. J. Plant Growth Regul. 21, 137-145. doi: 10.1007/s003440010052

Braun, M., and Limbach, C. (2006). Rhizoids and protonemata of characean algae: model cells for research on polarized growth and plant gravity sensing. Protoplasma 229, 133-142. doi: 10.1007/s00709-0060208-209

Caspar, T., and Pickard, B. G. (1989). Gravitropism in a starchless mutant of Arabidopsis: implications for the starch-statolith theory of gravity sensing. Planta 177, 185-197. doi: 10.1007/BF003 92807

Chatterjee, A., Porterfield, D. M., Smith, P. S., and Roux, S. J. (2000). Gravitydirected calcium current in germinating spores of Ceratopteris richardii. Planta 210, 607-610. doi: 10.1007/s004250050050

Chen, I. C., Huang, I. C., Liu, M. J., Wang, Z. G., Chung, S. S., and Hsieh, H. L. (2007). Glutathione S-transferase interacting with far-red insensitive 219 is involved in phytochrome A-mediated signaling in Arabidopsis. Plant Physiol. 143, 1189-1202. doi: 10.1104/pp.106.094185

Chen, R., Hilson, P., Sedbrook, J., Rosen, E., Caspar, T., and Masson, P. H. (1998). The Arabidopsis thaliana AGRAVITROPIC 1 gene encodes a component of the polar-auxin-transport efflux carrier. Proc. Natl. Acad. Sci. U.S.A. 95, 1511215117. doi: 10.1073/pnas.95.25.15112

Chen, R., Rosen, E., and Masson, P. H. (1999). Gravitropism in higher plants. Plant Physiol. 120, 343-350. doi: 10.1104/pp.120.2.343.

Correll, M. J., Pyle, T. P., Millar, K. D., Sun, Y., Yao, J., Edelmann, R. E., et al. (2013). Transcriptome analyses of Arabidopsis thaliana seedlings grown in space: implications for gravity-responsive genes. Planta 238, 519-533. doi: 10.1007/s00425-013-1909-x 
Cowles, J. R., Scheld, H. W., Lemay, R., and Peterson, C. (1984). Growth and lignification in seedlings exposed to eight days of microgravity. Ann. Bot. 54, 33-48.

Dolan, L., Janmaat, K., Willemsen, V., Linstead, P., Poethig, S., Roberts, K., et al. (1993). Cellular organisation of the Arabidopsis thaliana root. Development 119, 71-84.

Dong, Z., Jiang, C., Chen, X., Zhang, T., Ding, L., Song, W., et al. (2013). Maize LAZY1 mediates shoot gravitropism and inflorescence development through regulating auxin transport, auxin signaling, and light response. Plant Physiol. 163, 1306-1322. doi: 10.1104/pp.113.227314

Esmon, C. A., Tinsley, A. G., Ljung, K., Sandberg, G., Hearne, L. B., and Liscum, E. (2006). A gradient of auxin and auxin-dependent transcription precedes tropic growth responses. Proc. Natl. Acad. Sci. U.S.A. 103, 236-241. doi: 10.1073/pnas.0507127103

Fasano, J. M., Massa, G. D., and Gilroy, S. (2002). Ionic signaling in plant responses to gravity and touch. J. Plant Growth Regul. 21, 71-88. doi: 10.1007/s003440010049

Fasano, J. M., Swanson, S. J., Blancaflor, E. B., Dowd, P. E., Kao, T. H., and Gilroy, S. (2001). Changes in root cap $\mathrm{pH}$ are required for the gravity response of the Arabidopsis root. Plant Cell 13, 907-921. doi: 10.1105/tpc.13.4.907

Fengler, S., Spirer, I., Neef, M., Ecke, M., Nieselt, K., and Hampp, R. (2015). A whole-genome microarray study of Arabidopsis thaliana semisolid callus cultures exposed to microgravity and nonmicrogravity related spaceflight conditions for 5 days on board of Shenzhou 8. Biomed. Res. Int. 2015:547495. doi: 10.1155/2015/547495

Ferl, R. J., Koh, J., Denison, F., and Paul, A.-L. (2015). Spaceflight induces specific alterations in the proteomes of Arabidopsis. Astrobiology 15, 32-56. doi: 10.1089/ast.2014.1210

Frank, A. B. (1868). "Über die durch die Schwerkraft verursachten Bewegungen von Pflanzentheilen," in Beiträge zur Pflanzenphysiologie (Leipzig: Verlag von Wilhelm Engelmann), 1-99.

Friml, J. (2003). Auxin transport - shaping the plant. Curr. Opin. Plant Biol 6, 7-12. doi: 10.1016/S1369526602000031

Friml, J., Benkova, E., Blilou, I., Wisniewska, J., Hamann, T., Ljung, K., et al. (2002a). AtPIN4 mediates sink-driven auxin gradients and root patterning in Arabidopsis. Cell 108, 661-673. doi: 10.1016/S0092-8674(02) 00656-6

Friml, J., Wisniewska, J., Benkova, E., Mendgen, K., and Palme, K. (2002b). Lateral relocation of auxin efflux regulator PIN3 mediates tropism in Arabidopsis. Nature 415, 806-809. doi: 10.1038/415806a

Fukaki, H., Wysocka-Diller, J., Kato, T., Fujisawa, H., Benfey, P. N., and Tasaka, M. (1998). Genetic evidence that the endodermis is essential for shoot gravitropism in Arabidopsis thaliana. Plant J. 14, 425-430. doi: 10.1046/j.1365313X.1998.00137.x

Ganguly, A., Lee, S. H., and Cho, H. T. (2012). Functional identification of the phosphorylation sites of Arabidopsis PIN-FORMED3 for its subcellular localization and biological role. Plant J. 71, 810-823. doi: 10.1111/j.1365313X.2012.05030.x

Geldner, N., Richter, S., Vieten, A., Marquardt, S., Torres-Ruiz, R. A., Mayer, U., et al. (2004). Partial loss-of-function alleles reveal a role for GNOM in auxin transport-related, post-embryonic development of Arabidopsis. Development 131, 389-400. doi: 10.1242/dev.00926

Grebe, M. (2005). Growth by auxin: when a weed needs acid. Science 310, 60-61. doi: $10.1126 /$ science. 1119735

Guan, C., Rosen, E. S., Boonsirichai, K., Poff, K. L., and Masson, P. H. (2003). The ARG1-LIKE2 gene of Arabidopsis functions in a gravity signal transduction pathway that is genetically distinct from the PGM pathway. Plant Physiol. 133, 100-112. doi: 10.1104/pp.103.023358

Haberlandt, G. (1900). Über die Perzeption des geotropischen Reizes. Ber. Dtsch. Bot. Ges. 18, 261-272.

Häder, D.-P., Richter, P., and Lebert, M. (2006). Signal transduction in gravisensing of flagellates. Signal Trans. 6, 422-431. doi: 10.1002/sita.200600104

Hasenstein, K. H., and Evans, M. L. (1988). Effects of cations on hormone transport in primary roots of Zea mays. Plant Physiol. 86, 890-894. doi: 10.1104/pp.86.3.890

Hausmann, N., Fengler, S., Hennig, A., Franz-Wachtel, M., Hampp, R., and Neef, M. (2014). Cytosolic calcium, hydrogen peroxide and related gene expression and protein modulation in Arabidopsis thaliana cell cultures respond immediately to altered gravitation: parabolic flight data. Plant Biol. 16, 120-128. doi: $10.1111 /$ plb.12051

Heilmann, I., Shin, J., Huang, J., Perera, I. Y., and Davies, E. (2001). Transient dissociation of polyribosomes and concurrent recruitment of calreticulin and calmodulin transcripts in gravistimulated maize pulvini. Plant Physiol. 127, 1193-1203. doi: 10.1104/pp.010538

Herranz, R., Anken, R., Boonstra, J., Braun, M., Christianen, P. C., De Geest, M., et al. (2013a). Ground-based facilities for simulation of microgravity: organismspecific recommendations for their use, and recommended terminology. Astrobiology 13, 1-17. doi: 10.1089/ast.2012.0876

Herranz, R., Manzano, A. I., Van Loon, J. J., Christianen, P. C., and Medina, F. J. (2013b). Proteomic signature of Arabidopsis cell cultures exposed to magnetically induced hyper- and microgravity environments. Astrobiology 13, 217-224. doi: 10.1089/ast.2012.0883

Hoson, T., Soga, K., Mori, R., Saiki, M., Nakamura, Y., Wakabayashi, K., et al. (2002). Stimulation of elongation growth and cell wall loosening in rice coleoptiles under microgravity conditions in space. Plant Cell Physiol. 43, 1067-1071. doi: 10.1093/pcp/pcf126

Hoson, T., Soga, K., Wakabayashi, K., Kamisaka, S., and Tanimoto, E. (2003). Growth and cell wall changes in rice roots during spaceflight. Plant Soil 255, 19-26. doi: 10.1023/A:1026105431505

Hou, G., Kramer, V. L., Wang, Y. S., Chen, R., Perbal, G., Gilroy, S., et al. (2004). The promotion of gravitropism in Arabidopsis roots upon actin disruption is coupled with the extended alkalinization of the columella cytoplasm and a persistent lateral auxin gradient. Plant J. 39, 113-125. doi: 10.1111/j.1365313X.2004.02114.x

Hou, G., Mohamalawari, D. R., and Blancaflor, E. B. (2003). Enhanced gravitropism of roots with a disrupted cap actin cytoskeleton. Plant Physiol. 131, 1360-1373. doi: 10.1104/pp.014423

Hu, L., Mei, Z., Zang, A., Chen, H., Dou, X., Jin, J., et al. (2013). Microarray analyses and comparisons of upper or lower flanks of rice shoot base preceding gravitropic bending. PLoS ONE 8:e74646. doi: 10.1371/journal.pone.0074646

Huang, F., Zago, M. K., Abas, L., Van Marion, A., Galvan-Ampudia, C. S., and Offringa, R. (2010). Phosphorylation of conserved PIN motifs directs Arabidopsis PIN1 polarity and auxin transport. Plant Cell 22, 1129-1142. doi: 10.1105/tpc.109.072678

Ingber, D. E. (1997). Tensegrity: the architectural basis of cellular mechanotransduction. Annu. Rev. Physiol. 59, 575-599. doi: 10.1146/annurev.physiol.59.1.575

Joo, J. H., Bae, Y. S., and Lee, J. S. (2001). Role of auxin-induced reactive oxygen species in root gravitropism. Plant Physiol. 126, 1055-1060. doi: 10.1104/pp.126.3.1055

Kamada, M., Higashitani, A., and Ishioka, N. (2005). Proteomic analysis of Arabidopsis root gravitropism. Biol. Sci. Space 19, 148-154. doi: 10.2187/bss.19.148

Kimbrough, J. M., Salinas-Mondragon, R., Boss, W. F., Brown, C. S., and Sederoff, H. W. (2004). The fast and transient transcriptional network of gravity and mechanical stimulation in the Arabidopsis root apex. Plant Physiol. 136, 27902805. doi: 10.1104/pp.104.044594

Kiss, J. Z. (2000). Mechanisms of the early phases of plant gravitropism. CRC Crit. Rev. Plant Sci. 19, 551-573. doi: 10.1080/07352680091 139295

Kiss, J. Z., Guisinger, M. M., Miller, A. J., and Stackhouse, K. S. (1997). Reduced gravitropism in hypocotyls of starch-deficient mutants of Arabidopsis. Plant Cell Physiol. 38, 518-525. doi: 10.1093/oxfordjournals.pcp.a029199

Kiss, J. Z., Hertel, R., and Sack, F. D. (1989). Amyloplasts are necessary for full gravitropic sensitivity in roots of Arabidopsis thaliana. Planta 177, 198-206. doi: 10.1007/BF00392808

Kiss, J. Z., and Sack, F. D. (1989). Reduced gravitropic sensitivity in roots of a starch-deficient mutant of Nicotiana sylvestris. Planta 180, 123-130. doi: 10.1007/BF02411418

Kleine-Vehn, J., Ding, Z., Jones, A. R., Tasaka, M., Morita, M. T., and Friml, J. (2010). Gravity-induced PIN transcytosis for polarization of auxin fluxes in gravity-sensing root cells. Proc. Natl. Acad. Sci. U.S.A. 51, 22344-22349. doi: $10.1073 /$ pnas. 1013145107

Kleine-Vehn, J., and Friml, J. (2008). Polar targeting and endocytic recycling in auxin-dependent plant development. Annu. Rev. Cell Dev. Biol. 24, 447-473. doi: 10.1146/annurev.cellbio.24.110707.175254 
Klymchuk, D. O., Brown, C. S., Chapman, D. K., Vorobyova, T. V., and Martyn, G. M. (2001). Cytochemical localization of calcium in soybean root cap cells in microgravity. Adv. Space Res. 27, 967-972. doi: 10.1016/S0273-1177(01)00160-0

Kuznetsov, O. A., and Hasenstein, K. H. (1996). Intracellular magnetophoresis of amyloplasts and induction of root curvature. Planta 198, 87-94. doi: 10.1007/BF00197590

Kwon, T., Sparks, J. A., Nakashima, J., Allen, S. N., Tang, Y., and Blancaflor, E. B. (2015). Transcriptional response of Arabidopsis seedlings during spaceflight reveals peroxidase and cell wall remodeling genes associated with root hair development. Am. J. Bot. 102, 21-35. doi: 10.3732/ajb.1400458

Leitz, G., Kang, B. H., Schoenwaelder, M. E., and Staehelin, L. A. (2009). Statolith sedimentation kinetics and force transduction to the cortical endoplasmic reticulum in gravity-sensing Arabidopsis columella cells. Plant Cell 21, 843-860. doi: $10.1105 /$ tpc.108.065052

Limbach, C., Hauslage, J., Schafer, C., and Braun, M. (2005). How to activate a plant gravireceptor. Early mechanisms of gravity sensing studied in characean rhizoids during parabolic flights. Plant Physiol. 139, 1030-1040. doi: 10.1104/pp.105.068106

Löfke, C., Zwiewka, M., Heilmann, I., Van Montagu, M. C., Teichmann, T., and Friml, J. (2013). Asymmetric gibberellin signaling regulates vacuolar trafficking of PIN auxin transporters during root gravitropism. Proc. Natl. Acad. Sci. U.S.A. 110, 3627-3632. doi: 10.1073/pnas.1300107110

Lopez, D., Tocquard, K., Venisse, J. S., Legue, V., and Roeckel-Drevet, P. (2014). Gravity sensing, a largely misunderstood trigger of plant orientated growth. Front. Plant Sci. 5:610. doi: 10.3389/fpls.2014.00610

Luschnig, C., Gaxiola, R. A., Grisafi, P., and Fink, G. R. (1998). EIR1, a root-specific protein involved in auxin transport, is required for gravitropism in Arabidopsis thaliana. Genes Dev. 12, 2175-2187. doi: 10.1101/gad.12.14.2175

MacCleery, S. A., and Kiss, J. Z. (1999). Plastid sedimentation kinetics in roots of wild-type and starch-deficient mutants of Arabidopsis. Plant Physiol. 120, 183-192. doi: 10.1104/pp.120.1.183

Mahonen, A. P., Ten Tusscher, K., Siligato, R., Smetana, O., Diaz-Trivino, S., Salojarvi, J., et al. (2014). PLETHORA gradient formation mechanism separates auxin responses. Nature 515, 125-129. doi: 10.1038/nature13663

Martzivanou, M., Babbick, M., Cogoli-Greuter, M., and Hampp, R. (2006). Microgravity-related changes in gene expression after short-term exposure of Arabidopsis thaliana cell cultures. Protoplasma 229, 155-162. doi: 10.1007/s00709-006-0203-201

Mazars, C., Briere, C., Grat, S., Pichereaux, C., Rossignol, M., Pereda-Loth, V., et al. (2014a). Microsome-associated proteome modifications of Arabidopsis seedlings grown on board the International Space Station reveal the possible effect on plants of space stresses other than microgravity. Plant Signal. Behav. 9:e29637. doi: 10.4161/psb.29637

Mazars, C., Brière, C., Grat, S., Pichereaux, C., Rossignol, M., Pereda-Loth, V., et al. (2014b). Microgravity induces changes in microsome-associated proteins of arabidopsis seedlings grown on board the international space station. PLoS ONE 9:e91814. doi: 10.1371/journal.pone.0091814

McClure, B. A., and Guilfoyle, T. (1989). Rapid redistribution of auxin-regulated RNAs during gravitropism. Science 243, 91-93. doi: 10.1126/science.11540631

Medina, F. J., and Herranz, R. (2010). Microgravity environment uncouples cell growth and cell proliferation in root meristematic cells: the mediator role of auxin. Plant Signal. Behav. 5, 176-179. doi: 10.4161/psb.5.2. 10966

Millar, K. D., and Kiss, J. Z. (2013). Analyses of tropistic responses using metabolomics. Am. J. Bot. 100, 79-90. doi: 10.3732/ajb.1200316

Morita, M. T. (2010). Directional gravity sensing in gravitropism. Annu. Rev. Plant Biol. 61, 705-720. doi: 10.1146/annurev.arplant.043008. 092042

Moseyko, N., Zhu, T., Chang, H. S., Wang, X., and Feldman, L. J. (2002). Transcription profiling of the early gravitropic response in Arabidopsis using high-density oligonucleotide probe microarrays. Plant Physiol. 130, 720-728. doi: $10.1104 /$ pp.009688

Muday, G. K., Rahman, A., and Binder, B. M. (2012). Auxin and ethylene: collaborators or competitors? Trends Plant Sci 17, 181-195. doi: 10.1016/j.tplants.2012.02.001

Nedukha, O. M., Kordyum, E. L., Brown, C., and Chapman, D. (2001). The interaction of microgravity and ethylene on the ultrastructure cell and $\mathrm{Ca}^{2+}$ localization in soybean hook hypocotyl. J. Gravit. Physiol. 8, P49-P50.
Ottenschlager, I., Wolff, P., Wolverton, C., Bhalerao, R. P., Sandberg, G., Ishikawa, H., et al. (2003). Gravity-regulated differential auxin transport from columella to lateral root cap cells. Proc. Natl. Acad. Sci. U.S.A. 100, 2987-2991. doi: 10.1073/pnas.0437936100

Paciorek, T., Zazimalova, E., Ruthardt, N., Petrasek, J., Stierhof, Y. D., KleineVehn, J., et al. (2005). Auxin inhibits endocytosis and promotes its own efflux from cells. Nature 435, 1251-1256. doi: 10.1038/nature03633

Paudyal, R., Jamaluddin, A., Warren, J. P., Doyle, S. M., Robert, S., Warriner, S. L., et al. (2014). Trafficking modulator TENin1 inhibits endocytosis, causes endomembrane protein accumulation at the pre-vacuolar compartment and impairs gravitropic response in Arabidopsis thaliana. Biochem. J. 460, 177-185. doi: 10.1042/bj20131136

Paul, A. L., Amalfitano, C. E., and Ferl, R. J. (2012a). Plant growth strategies are remodeled by spaceflight. BMC Plant Biol. 12:232. doi: 10.1186/14712229-12-232

Paul, A. L., Zupanska, A. K., Ostrow, D. T., Zhang, Y., Sun, Y., Li, J. L., et al. (2012b). Spaceflight transcriptomes: unique responses to a novel environment. Astrobiology 12, 40-56. doi: 10.1089/ast.2011.0696

Paul, A.-L., Popp, M. P., Gurley, W. B., Guy, C., Norwood, K. L., and Ferl, R. J. (2005). Arabidopsis gene expression patterns are altered during spaceflight. Adv. Space Res. 36, 1175-1181. doi: 10.1016/j.asr.2005.03.066

Paul, A.-L., Zupanska, A., Schultz, E., and Ferl, R. (2013). Organ-specific remodeling of the Arabidopsis transcriptome in response to spaceflight. BMC Plant Biol. 13:112. doi: 10.1186/1471-2229-13-112

Perbal, G. (1999). Gravisensing in roots. Adv. Space Res. 24, 723-729. doi: 10.1016/S0273-1177(99)00405-6

Perbal, G., and Driss-Ecole, D. (2003). Mechanotransduction in gravisensing cells. Trends Plant Sci. 8, 498-504. doi: 10.1016/j.tplants.2003. 09.005

Perera, I. K., Heilmann, I., Chang, S. C., Boss, W. F., and Kaufman, P. B. (2001a). A role for inositol 1,4,5-trisphosphate in gravitropic signaling and the retention of cold-perceived gravistimulation of oat shoot pulvini. Plant Physiol. 125, 1499-1507. doi: 10.1104/pp.125.3.1499

Perera, I. Y., Heilmann, I., Chang, S. C., Boss, W. F., and Kaufman, P. B. (2001b). A role for inositol 1,4,5-trisphosphate in gravitropic signaling and the retention of cold-perceived gravistimulation of oat shoot pulvini. Plant Physiol. 125, 1499-1507. doi: 10.1104/pp.125.3.1499

Perera, I. Y., Heilmann, I., and Boss, W. F. (1999). Transient and sustained increases in inositol 1,4,5-trisphosphate precede the differential growth response in gravistimulated maize pulvini. Proc. Natl. Acad. Sci. U.S.A. 96, 5838-5843. doi: 10.1073/pnas.96.10.5838

Pitzschke, A., and Hirt, H. (2006). Mitogen-Activated protein kinases and reactive oxygen species signaling in plants. Plant Physiol. 141, 351-356. doi: $10.1104 /$ pp.106.079160

Plieth, C., and Trewavas, A. J. (2002). Reorientation of seedlings in the earth's gravitational field induces cytosolic calcium transients. Plant Physiol. 129, 786-796. doi: 10.1104/pp.011007

Porterfield, D. M. (2002). The biophysical limitations in physiological transport and exchange in plants grown in microgravity. J Plant Growth Regul. 21, 177-190. doi: 10.1007/s003440010054

Porterfield, D. M., Matthews, S. W., Daugherty, C. J., and Musgrave, M. E. (1997). Spaceflight exposure effects on transcription, activity, and localization of alcohol dehydrogenase in the roots of Arabidopsis thaliana. Plant Physiol. 113, 685-693. doi: 10.1104/pp.113.3.685

Sack, F. D. (1991). Plant gravity sensing. Int. Rev. Cytol. 127, 193-252. doi: 10.1016/S0074-7696(08)60695-6

Sack, F. D. (1997). Plastids and gravitropic sensing. Planta 203, S63-S68. doi: $10.1007 / \mathrm{Pl} 00008116$

Salmi, M., Ul Haque, A., Bushart, T., Stout, S., Roux, S., and Porterfield, D. M. (2011). Changes in gravity rapidly alter the magnitude and direction of a cellular calcium current. Planta 233, 911-920. doi: 10.1007/s00425-0101343-1342

Salmi, M. L., and Roux, S. J. (2008). Gene expression changes induced by space flight in single-cells of the fern Ceratopteris richardii. Planta 229, 151-159. doi: 10.1007/s00425-008-0817-y

Sato, E. M., Hijazi, H., Bennett, M. J., Vissenberg, K., and Swarup, R. (2015). New insights into root gravitropic signalling. J. Exp. Bot. 66, 2155-2165. doi: $10.1093 / j x b /$ eru515 
Schenck, C. A., Nadella, V., Clay, S. L., Lindner, J., Abrams, Z., and Wyatt, S. E. (2013). A proteomics approach identifies novel proteins involved in gravitropic signal transduction. Am. J. Bot. 100, 194-202. doi: 10.3732/ajb.1200339

Schüler, O., Krause, L., Görög, M., Hauslage, J., Kesseler, L., Böhmer, M., et al. (2015). ARADISH - development of a standardized plant growth chamber for experiments in gravitational biology using ground based facilities. Microgr. Sci. Technol. 1-9. doi: 10.1007/s12217-015-9454-9459.

Sedbrook, J. C., Chen, R. J., and Masson, P. H. (1999). ARG1 (Altered Response to Gravity) encodes a DnaJ-like protein that potentially interacts with the cytoskeleton. Proc. Natl. Acad. Sci. U.S.A. 96, 1140-1145. doi: 10.1073/pnas.96.3.1140

Sievers, A., Buchen, B., Volkmann, D., and Hejnowicz, Z. (1991). "Role of the cytoskeleton in gravity perception," in The Cytoskeletal Basis of Plant Growth and Form, ed. C. W. Lloyd (London: Academic Press), 169-182.

Sinclair, W., and Trewavas, A. J. (1997). Calcium in gravitropism. A reexamination. Planta 203, S85-S90. doi: 10.1007/PL00008120

Soga, K., Wakabayashi, K., Kamisaka, S., and Hoson, T. (2002). Stimulation of elongation growth and xyloglucan breakdown in Arabidopsis hypocotyls under microgravity conditions in space. Planta 215, 1040-1046. doi: 10.1007/s00425002-0838-x

Soga, K., Wakabayashi, K., Kamisaka, S., and Hoson, T. (2003). Growth restoration in azuki bean and maize seedlings by removal of hypergravity stimuli. Adv. Space Res. 31, 2269-2274. doi: 10.1016/S0273-1177(03) 00254-0

Soh, H., Auh, C., Soh, W.-Y., Han, K., Kim, D., Lee, S., et al. (2011). Gene expression changes in Arabidopsis seedlings during short- to long-term exposure to 3-D clinorotation. Planta 234, 255-270. doi: 10.1007/s00425-011-1395-y

Stanga, J. P., Boonsirichai, K., Sedbrook, J. C., Otegui, M. S., and Masson, P. H. (2009). A role for the TOC complex in Arabidopsis root gravitropism. Plant Physiol. 149, 1896-1905. doi: 10.1104/pp.109.135301

Staves, M. P. (1997). Cytoplasmic streaming and gravity sensing in Chara internodal cells. Planta 203, S79-S84. doi: 10.1007/pl00008119

Staves, M. P., Wayne, R., and Leopold, A. C. (1997). The effect of the external medium on the gravitropic curvature of rice (Oryza sativa, Poaceae) roots. Am. J. Bot. 84, 1522-1529. doi: 10.2307/2446613

Stinemetz, C. L., Kuzmanoff, K. M., Evans, M. L., and Jarrett, H. W. (1987). Correlation between calmodulin activity and gravitropic sensitivity in primary roots of maize. Plant Physiol. 84, 1337-1342. doi: 10.1104/pp.84.4.1337

Strohm, A. K., Barrett-Wilt, G. A., and Masson, P. H. (2014). A functional TOC complex contributes to gravity signal transduction in Arabidopsis. Front. Plant Sci. 5:148. doi: 10.3389/fpls.2014.00148

Stutte, G., Monje, O., Hatfield, R., Paul, A., Ferl, R., and Simone, C. (2006). Microgravity effects on leaf morphology, cell structure, carbon metabolism and mRNA expression of dwarf wheat. Planta 224, 1038-1049. doi: 10.1007/s00425006-0290-4

Sugimoto, M., Oono, Y., Gusev, O., Matsumoto, T., Yazawa, T., Levinskikh, M. A., et al. (2014). Genome-wide expression analysis of reactive oxygen species gene network in Mizuna plants grown in long-term spaceflight. BMC Plant Biol 14:4. doi: 10.1186/1471-2229-14-14

Sukumar, P., Edwards, K. S., Rahman, A., Delong, A., and Muday, G. K. (2009). PINOID kinase regulates root gravitropism through modulation of PIN2dependent basipetal auxin transport in Arabidopsis. Plant Physiol. 150, 722-735. doi: $10.1104 /$ pp.108.131607

Swarup, R., Friml, J., Marchant, A., Ljung, K., Sandberg, G., Palme, K., et al. (2001). Localization of the auxin permease AUX1 suggests two functionally distinct hormone transport pathways operate in the Arabidopsis root apex. Genes Dev. 15, 2648-2653. doi: 10.1101/gad.210501

Swindell, W. R., Huebner, M., and Weber, A. P. (2007). Transcriptional profiling of Arabidopsis heat shock proteins and transcription factors reveals extensive overlap between heat and non-heat stress response pathways. BMC Genomics 8:125. doi: 10.1186/1471-2164-8-125
Tan, C., Wang, H., Zhang, Y., Qi, B., Xu, G., and Zheng, H. (2011). A proteomic approach to analyzing responses of Arabidopsis thaliana root cells to different gravitational conditions using an agravitropic mutant, pin2 and its wild type. Proteome Sci. 9, 72. doi: 10.1186/1477-5956-9-72

Taniguchi, M., Nakamura, M., Tasaka, M., and Morita, M. T. (2014). Identification of gravitropic response indicator genes in Arabidopsis inflorescence stems. Plant Signal. Behav. 9:e29570. doi: 10.4161/psb.29570

Toyota, M., Furuichi, T., Tatsumi, H., and Sokabe, M. (2008). Cytoplasmic calcium increases in response to changes in the gravity vector in hypocotyls and petioles of Arabidopsis seedlings. Plant Physiol. 146, 505-514. doi: 10.1104/pp.107.106450

Valster, A. H., and Blancaflor, E. B. (2008). "Mechanisms of gravity perception in higher plants," in Plant Tropisms (Hoboken, MA: Blackwell Publishing Ltd), 3-19.

Volkmann, D., and Baluska, F. (1999). Actin cytoskeleton in plants: from transport networks to signaling networks. Microsc. Res. Technol. 47, 135-154. doi: 10.1002/sic1097-0029

Wang, H., Zheng, H. Q., Sha, W., Zeng, R., and Xia, Q. C. (2006). A proteomic approach to analysing responses of Arabidopsis thaliana callus cells to clinostat rotation. J. Exp. Bot. 57, 827-835. doi: 10.1093/Jxb/Erj066

Wayne, R., and Staves, M. P. (1996). A down to earth model of gravisensing or Newton's Law of Gravitation from the apple's perspective. Physiol. Plant. 98, 917-921. doi: 10.1111/j.1399-3054.1996.tb06703.x

Wayne, R., Staves, M. P., and Leopold, A. C. (1990). Gravity-dependent polarity of cytoplasmic streaming in Nitellopsis. Protoplasma 155, 43-57. doi: 10.1007/BF01322614

Went, F., and Thimann, K. (1937). Phytohormones (New York, NY: Macmillan).

Whitford, R., Fernandez, A., Tejos, R., Perez, A. C., Kleine-Vehn, J., Vanneste, S., et al. (2012). GOLVEN secretory peptides regulate auxin carrier turnover during plant gravitropic responses. Dev. Cell 22, 678-685. doi: 10.1016/j.devcel.2012.02.002

Wyatt, S. E., Rashotte, A. M., Shipp, M. J., Robertson, D., and Muday, G. K. (2002). Mutations in the Gravity persistence signal loci in arabidopsis disrupt the perception and/or signal transduction of gravitropic stimuli. Plant Physiol. 130, 1426-1435. doi: 10.1104/pp.102.010579

Yoder, T. L., Zheng, H. Q., Todd, P., and Staehelin, L. A. (2001). Amyloplast sedimentation dynamics in maize columella cells support a new model for the gravity-sensing apparatus of roots. Plant Physiol. 125, 1045-1060. doi: 10.1104/pp.125.2.1045

Zadnikova, P., Smet, D., Zhu, Q., Van Der Straeten, D., and Benkova, E. (2015). Strategies of seedlings to overcome their sessile nature: auxin in mobility control. Front. Plant Sci. 6:218. doi: 10.3389/fpls.2015.00218

Zhang, Y., Wang, L., Xie, J., and Zheng, H. (2015). Differential protein expression profiling of Arabidopsis thaliana callus under microgravity on board the Chinese SZ-8 spacecraft. Planta 241, 475-488. doi: 10.1007/s00425-014-2196-x

Zheng, H. Q., and Staehelin, L. A. (2001). Nodal endoplasmic reticulum, a specialized form of endoplasmic reticulum found in gravity-sensing root tip columella cells. Plant Physiol. 125, 252-265. doi: 10.1104/pp.125.1.252

Zupanska, A., Denison, F., Ferl, R., and Paul, A.-L. (2013). Spaceflight engages heat shock protein and other molecular chaperone genes in tissue culture cells of Arabidopsis thaliana. Am. J. Bot. 100, 235-248. doi: 10.3732/ajb.1200343

Conflict of Interest Statement: The authors declare that the research was conducted in the absence of any commercial or financial relationships that could be construed as a potential conflict of interest.

Copyright (c) 2015 Schüler, Hemmersbach and Böhmer. This is an open-access article distributed under the terms of the Creative Commons Attribution License (CC BY). The use, distribution or reproduction in other forums is permitted, provided the original author(s) or licensor are credited and that the original publication in this journal is cited, in accordance with accepted academic practice. No use, distribution or reproduction is permitted which does not comply with these terms. 